\title{
Die Macht
}

\section{des Faktischen}

Liebe Leserin, lieber Leser,

die Beziehung zwischen OEM und Zulieferer ist keine einfache. Das zeigte jüngst wieder die Auseinandersetzung zwischen Volkswagen und den zur Unternehmensgruppe Prevent gehörenden Unternehmen exemplarisch auf. Zwar wurde der Streit relativ zügig beigelegt, aber am Ende hat keine der Vertragsparteien gewonnen.

Die beteiligten Zulieferer haben sich zwar - durchaus branchenunüblich gewehrt, laufen aber Gefahr, zukünftig bei lukrativen Großaufträgen leer auszugehen, weil sie nun als Risikofaktor gelten. Der OEM wiederum hat sich zwar letztendlich durchgesetzt, trägt aber einen nicht unerheblichen Imageschaden aus diesem Streit davon.

Drittens aber - und das ist der eigentliche Punkt - führt dieser Streit die Abhängigkeit der Automobilhersteller von ihren Zulieferern vor Augen. In den vergangenen Jahren haben die Hersteller vermehrt Entwicklungsaufgaben an ihre Zulieferer und Dienstleister delegiert, nicht zuletzt um Kosten zu sparen. Folge ist, dass die externen Partner nicht nur rund 70 \% der Wertschöpfung eines Automobils generieren, sondern mittlerweile von entscheidender Bedeutung für die Innovationskraft der OEMs sind. Sie profitierten dabei von der zunehmenden Notwendigkeit einer vernetzten Entwicklung in den Bereichen Fahrzeug- und Antriebsentwicklung, von der Lösungen im systemischen Kontext erwartet werden. Faktisch kann heute kein Automobilhersteller ohne seine Zulieferer und Dienstleister auch nur ein Fahrzeug auf die Straße bringen. Und diese faktische Macht wird vor allem bei Zukunftsthemen wie Batterietechnologien, elektrifizierten Antrieben oder automatisiertem Fahren noch weiter wachsen.

Vor diesem Hintergrund haben die OEMs großes Glück, dass die strategische Bedeutung der deutschen Automobilzulieferer von wenigen Ausnahmen abgesehen in krassem Missverhältnis zu ihrer Bekanntheit steht, wie eine aktuelle Studie des Nürnberger Marktforschungsinstituts Puls kürzlich bestätigte. Dennoch wäre aufgrund der hohen Relevanz von Zulieferern und Dienstleistern eine echte Partnerschaft auf Augenhöhe das Gebot der Stunde.

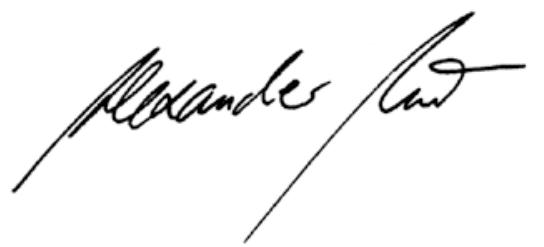

Dr. Alexander Heintzel Chefredakteur

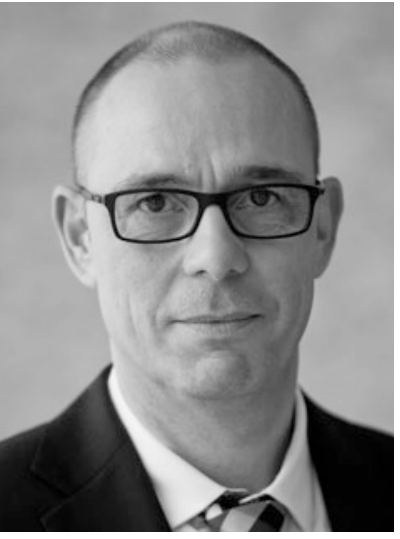

Wir

\section{entwickeln, was bewegt.}

IAV - Ihr Partner

für Automotive Engineering 